\title{
Novel Coronavirus (COVID-19) and Human Psychology: Findings and Discussion
}

\author{
Md. Amir Hossain*
}

PhD (Research Scholar) in English literature, Jahangirnagar University, Bangladesh

DOI: $\underline{10.36347 / \text { sjams.2020.v08i05.036 }}$

| Received: 25.04.2020 | Accepted: 07.05.2020 | Published: 28.05.2020

*Corresponding author: Md. Amir Hossain

Abstract

The aim of this paper is to look at the deadliest impacts of the novel coronavirus on the human psychology. It would like to focus on the pandemic outbreak of COVID-19 in the vulnerable countries of the world. Human body and brain, prejudice, hoarding supplies, social isolation, quarantine, home quarantine, anxiety, fear and panic, healing, remote activity, cognitive bias, acute stress disorder, conversion disorder, adjustment disorder, hypochondriasis, sleep disorder, social distancing, and racial conflicts are the major aspects of psychology and social sciences, which have been investigated in this study in the light of the critical comments made by critics and scholars, including Lunstad, Miller, Faulkner, Light, Ermon, Preston, Haselton, Saha, Levitsoka, Allport, Auestad, Roy and so on. Through their criticism, the paper attempts to look at psychological trauma and mental disorders owning to the infection and affection of the novel coronavirus. Moreover, the statements and opinions regarding the pandemic outbreak of the coronavirus and its severe impacts on the global population made by World Health organization, World Trade Organization, the Food and Agriculture Organization, and above all, American Psychiatric Association have been discussed in this research-work with a view to fostering the real picture of the fatal coronavirus.

Keywords: Novel Coronavirus (COVID-19), Pandemic Outbreak, Human Psychology, Quarantine, Social Distancing, and Racial Prejudice.

Copyright @ 2020: This is an open-access article distributed under the terms of the Creative Commons Attribution license which permits unrestricted use, distribution, and reproduction in any medium for non-commercial use (NonCommercial, or CC-BY-NC) provided the original author and source are credited.

\section{INTRODUCTION}

The novel COVID-19 pandemic outbreak, originating in the Wuhan city in China at the end of 2019 , begins to threaten the health and lives of the global population within in a very short time. Deadly contagious respiratory disease, like coronavirus, it swiftly impacts the governments, states, major regions and human public health systems globally. Consequently, all the governments declares the public health emergency of the national and the international concerns and adopts the immediate important measures in order that the coronavirus infection and limit the pandemic outbreak can be prevented. The lives and health system of the global communities have been threatened. The global, multi-level, and demanding stress-coping-adjustment has been increased very significantly. The social, economic, cultural, political, religious, and communal condition fall a tragic victim of the pandemic outbreak of the coronavirus.

As a result, the infected coronavirus disease has formed a shape of the global pandemic status. The World Health Organization provides some important guidelines so that the global community can tackle the difficult situation bio-medically and psychologically. While the preventive steps and medical actions are crying need at this stage, the emergency psychological crisis interventions for the global community are extremely critical and fatal. They include direct interventions for the patients, and indirect for relatives, caregivers, doctors, nurses, law-enforcing makers, and health care professionals, for which the psychological trauma and mental disorders are the culminating issues in the human psychology that is being greatly noticed, telecast, and published around the planet.

The whole world is now stagnant. People are deprived of mental pleasure and recreation. Children are also suffering from mental depression staying at home in sadder mind. There is no connection with academic environment and so, are lagging behind from the real target of life. Men, women and children are greatly tensed of the coronavirus pandemic outbreak when this terrifyingly difficult situation will come over and they will return to their better days. It seems that they are awaiting their safe return to the better days. Due to social distancing, nobody dares to come in contact with others; to get mixed together; never dare to participate 
in the meetings, games and sports, cultural programs, to gossip, to go to club, or to share their long awaited dreams. Many young boys and girls are deprived of education, examinations, and extra-curricular activities. Many poor people have lost their jobs; they are now jobless and have food at home and hunger and poverty around the world. People have no light of hope and expectation. Many immigrants are compelled to come back home; now are like vagabond. When they will go back to their destination is uncertain. In this way the whole global population are suffering, tormenting, or facing a variety of psychological disorders, which beggar description.

Social distancing, quarantine, and isolation has made millions of people keep themselves aloof from other communities; have made them homeless, jobless and foodless. Due to the impacts of the coronavirus pandemic outbreak on human psychology, it needs no telling the fact that the whole world has paralyzed economically, socially, politically, culturally, and religiously. All these things have brought about the dreadful changes on the minds of millions of people in the vulnerable countries of the world.

The psychology of global community is undergoing a significant change in all aspects due to novel coronavirus crisis. Many psychologists are concerned of mental agonies or mental disorder. Yet they are trying utmost to investigate the deepest thoughts from their psychological point of view. However, the current researcher wants to highlight the various impacts of the novel coronavirus on the human psychology, which is getting happened in the vulnerable countries of the world. Its object is to investigate human body and brain, prejudice, hoarding supplies, social isolation, quarantine, home quarantine, anxiety, fear and panic, healing, remote activity, cognitive bias, acute stress disorder, conversion disorder, adjustment disorder, hypochondriasis, sleep disorder, social distancing, and racial conflicts in the light of the critical comments made by the psychological critics and scholars, including Lunstad, Miller, Faulkner, Light, Ermon, Preston, Haselton, Saha, Levitsoka, Allport, Auestad, and Roy. How human psychology is changing negatively due to the infection and affection of the novel coronavirus is the sole purpose of this study[27]. It would like to show how human behavioral immune system has created racial prejudice in the panic mind of the common people in the vulnerable countries of the world. Our psychology shows that behavioral immune system deals with prejudices against the people who are not diseased but are characterized by visual characteristics that is deviated from those of the prototypical human being. Humans are seen to react abnormally while the situations of novel coronavirus pandemic outbreak are beyond human control.

\section{Impact on Human Body and Brain}

A man seems to be an unhappy state of mind when he is socially isolated from other human beings; he wants to thrive and fight for interaction. People who have weaker social relationships are $50 \%$ more likely to die of social isolation than those with the robust social bond. A 2015 meta-analysis upholds more than 308,000 people. While a man passes his days in a solitary mode, he is seen to smoke 15-cigarettes daily. For the reasons by depriving himself of social intersections does not feel good, even temporarily: Human body to mingle a man so that he can stay alive long term. In the regard a famous writer and researcher Julianne Holt-Lunstad in the Department of Psychology and Neuroscience, Brigham Young University, opines that if a man feels loneliness as an adaptive response due to hunger and thirst; it is such an unpleasant state of his mind that will certainly motivate him to seek out social bond just like a man seeks food to remove his hunger and thirst. Lunstad also says that in such a situation like a pandemic outbreak that requires a man to reduce or eliminate his face-to-face contact, which discomfort needs to be endured to stave off dangerous, and immediate effects are essential to control such difficult crisis.

I think that generally loneliness leads a man to traumatic point and makes him sad and depressive for which he is fully deprived of social intersection; if he is forced to stay in a lonely life for a short or long time at home or in a jungle, he will certainly seem to be lunatic or psychological state of mind. He will keep himself aloof from mental happiness and social pleasure. But in such a pandemic coronavirus situation, man will lose his mental pleasure and inner or outer sight of mind. In a quarantine situation a man will lead his life as a frog in a well or as a caged bird. Personally I have observed that a caged bird wants to set itself free from a cage. But it does not know that it has already been captured.

Another example may be drawn here to clarify the issue: if a man commits a dangerous crime or he murders someone that we can say what he has done is unforgivable, he must be hanged for murder; he will be captivated in a prison cell where no one will meet him and vice versa. He will have to stay in a prison cell in a lone manner until he will be hanged. Home quarantine is like a prison cell to some sorts of people in this coronavirus terrifyingly situation.

According to World Health organization, a man has to be quarantined for two weeks or even more until coronavirus pandemic outbreak is completely controlled. If such situation becomes lengthy, a man will be paralyzed economically, physical, mentally and socially; he will be deprived of all sorts of aspects. Coronavirus quarantine will bring for the global population debris in all sphere of human life. 
A man is cocooned for two weeks or more due to the infection of coronavirus or simply he has been working from home with a view to maintain his official duties; this reduction in physical activity can affect his mind and body.

Miller [1] points out the injured athletes may be a good example. Athletes have to endure emotional upheaval while they got injured very seriously in his bodily organs because they no longer have the coping mechanism that may manifest as sadness, irritation, frustration, anger, and severe emotion. What Miler means is that an athlete needs to take physical exercise and practices more and more as per rules of games and sports or in accordance with the suggestions of the coach. Otherwise, he will be emotionally disheartened owning to the lack of regular practice. In a quarantine situation, an athlete will fall victim of sadness, irritation, frustration, and anger.

According to US News \& World Report, elimination of human physical activity generally causes his muscles to atrophy. A study in the Journal of Applied Physiology shows that if a man remains inactive for the 2-weeks, it affects his heart and muscle mass severely. Another report shows that the obese adults who work out for 4-months begin to decline their improvements to their aerobic capacity, insulin sensitivity, and cholesterol. Human physical activity needs regular physical exercise to keep his body fit or to keep sound health. Those who are adults need psychical exercise daily basis, especially those who are suffering from diabetes must take physical exercise; otherwise, they will become sick. But in home quarantine situation, adults will take regular physical exercise, certainly it will impact on their body and mind.

The effects of a quarantine psychologically damages in the long term. According to February Research in The Lancet that the psychological effects of quarantines during the coronavirus pandemic outbreak lead to the traumatic stress symptoms, depression, confusion, anger, fear, anxiety, and substance misuse, for which the most vulnerable people suffer from mental health problems and mental disorders. He will be completely devoid of pleasure and enjoyment. A psychological effect of home quarantine makes a man frustrated, depressed, and fall in an unhappy state of mind.

If a man is affected by social isolation, his social bond will be declined gradually. As a result, social isolation will impact negatively on his personality and sensibility. In this regard, I can mention the statement of a psychologist Sherry Benton, who comments that if a man is an extrovert who thrives on social contact, the mental disorder will hit him harder. On the contrary, if a man is introvert, he will feels very comfortable and curl up on a couch with a book. Benton wants to show a difference between an extrovert and an introvert in this sense that an introvert will like to stay at home if he is devoted to reading books or keeps himself busy into domestic affairs. To him home quarantine will be suitable. On the contrary, to an extrovert, home quarantine will seem to be difficult if he likes to get mixed with the public gatherings or gossiping.

Those who are healthy or fatty should not linger and keep their distance from others. In this regard social distancing is a must to get rid of the infected coronavirus. The World Health Organization's Director General Tedros Adhanom Ghebreyesus says that if a man is not able to leave his house, he may take exercise through virtual system; he may be dancing to music, either he may do yoga, or walk up and down the stairs where he resides. His body and mind requires to do pushups, squats, lunges, and crunches. A chair may serve as a bench for trice dips. If a man may have a resistance band, he may take exercise at home. He may try squats or fast feet through squatting low and stepping in a place with the band around his legs above his knees to create tension and to strengthen. Ghebreyesus emphasizes on the truth that home exercise makes a man fit and keep his mind sound and fresh. To keep body fit and strong physical exercise is very much essential for a man.

To cope with a social quarantine mentally and emotionally or to have reduced social contact, to reach out to others through virtual system. Lunstad opines that quarantine has been less socially straining for ten years. She argues that tools, like Face Book or Skype may help a man relieve some short-term unpleasant responses to help him feel and maintain social interactions without putting himself at a great risk of the coronavirus infection. She recommends that being proactive about reaching out to others and asking how a man boosts his mental health since he experiences the perception of support, and his mental stress can be reduced. Lunstad further says that the silver lining to stay home like a detective enables him to slow down and connect with the people closest to a quarantined man. According to psychologists, a day-by-day breakdown of coronavirus symptoms shows how the disease, COVID-19, goes from bad to worse to cope with anxiety and fear [1].

\section{Impact on Prejudice}

While coronavirus is originated and then it begins to outbreak in the Wuhan city and other provinces gradually in China, the people of the world begin to leave the country in fear of the infection since the concerned authority of the World Health Organization warn about the fatal coronavirus' infection. Especially, many international students studying in Chinese universities are found to leave the countries. Many people regard coronavirus as Chinese virus since it has been originated in China. When the impacts of coronavirus begin to outbreak in many 
countries of the world, the Chinese are hated and despised by the people of other countries. As a result, travel restrictions on China are imposed in some countries of the world. Racial prejudice is created among human minds. People's attitudes the Chinese are negative and controversial globally. In this way, we may determine racial prejudice and communal discrimination through applying the psychological theory of behavioral immune system. If coronavirus would break out in Middle East, Europe, or Africa, same attitudes were found in the minds of the nations. In fact, it is very much difficult to ascertain when and where the global pandemic outbreak will occur. Racial conflicts are created among many nations of the world.

Now this study would like to show how human behavioral immune system creates racial prejudice in the panic mind of the common people. Psychological sciences show that behavioral immune system deal with prejudice and superstitious idea against the people who are not diseased but characterized by the visual characteristics for which they are deviated from the prototypical human being. The disease-avoidant process identifies behavioral immune system, which contributes to prejudices against obese and elderly individuals with physical disfigurements or disabilities [2] Moreover, behavioral immune system contributes to racial xenophobia [3]. Prejudice needs to be exaggerated under conditions where a man feels vulnerable to the potential transmission of an infectious disease.

A recent study on the behavioral immune system shows that when a man engages in the reticent and conservative forms of behavior, he will feel more vulnerable to disease transmission. For instance, while a threat of disease is made salient, he needs to be less extraverted or sociable [4]. An evolutionary psychological theory shows that an infectious disease, like coronavirus represents a threat to human survival. Because of such a constant threat of disease, people and other mammals evolve a wide variety of adaptations to cope with the pathogens [1] where they can be highlighted. [5].

Light points out that people are familiar with physiological immune system for which they can fight against the microscopic invaders owning to their immune cells and proteins. But, the psychologists think that people may react to the signs of disease in ways that help them avoid contaminated disease. One example is the feeling of disgust a man experiences while he smells something rotten. He shuts his mouth, holds his nose, or moves away. The reason is that a man is less likely to be infected by microbes that decompose the source of smell.
Behavioral immune system motivates human behavior that has less desirable social connections. Infected disease makes a man to hold xenophobic manner, which reflects a behavioral immune response. A man differs in his relative immunity to an infected disease, which results in immune systems to diseases and develop antibodies to fight against them. What Light means is that while a man is infected by a disease, being carried out by other people in the society or community; he may be at a lower risk of sickness from others. But, he is less likely to have immunity to disease when he lives far away from other people. Again, while a man is anxious of infected disease, people from other places and other groups show potential threats. In that case, they should try to avoid public gatherings or social interactions. She also points out that such type of human behavior can be an evolved adaptation that does not make such human behavior morally right or socially acceptable.

To avoid contact with the coronavirus infected countries of the glove ignores the fact that race is a poor signal of risk to spread coronavirus disease. Understanding the impact of behavioral immune system on human prejudice help a man fight against infection. Both anxious reaction to coronavirus and its impact on racial bias are cases of human mind try to keep man healthy and safe. [6] Behavioral immune system makes us understand how racial prejudice is created among human minds due to the pandemic outbreak of fatal coronavirus which is getting happened almost in many countries of the world.

According to Ermon [7], coronavirus is spreading rapidly around the world. Still now no vaccine or medicine has been discovered. Human behavior experts think that panic and fear are human nature. Xenophobic attitudes toward the Chinese are being noticed among many communities of the vulnerable countries, which are obviously hurtful to them. People are now seen not to eat at the Chinese restaurants and are rude to the Chinese. While some are seen to hoard supplies and cancelling flights others remain optimistic. For example, during the winter season rates are found to make holes in the ground so that they can hoard paddy for the rainy season. Similarly, in this terrifyingly difficult situation, many people are found to hoard supplies for the whole year.

Dominique Brossard $\left[{ }^{2}\right]$ points out: "This is just human psychology. We get scared of things we do not know." Humans react differently when situations are uncertain or unpredictable. Brossard also says: "Humans we are animals. We have a fear of the unknown. Whenever we know that something is happening that is not controlled or seems like there is
1. Pathogens are infectious germs, like virus, bacterium, protozoan, prion, viroid, or fungus.
2. The Chair and Professor of the Department of Life Sciences Communications, the University of Wisconsin-Madison, USA. 
uncertainty, we give it a lot of negative weight." These hysterical situations are happening around the world; and uncertainty and fear drive people to make rash decisions like panic-buying weeks of supplies.

Human psychology changes when a terrifyingly difficult situation, like pandemic outbreak of coronavirus occurs. Humans are found to fall in a great dilemma. Uncertainty works in human mind what may happen at any time. Again in the war affected or poverty affected countries, people feel less panic because they have already faced such terrific circumstances. In such situation, human psychology does not work in an equal manner.

Before the discovery of medicine, infectious diseases were the major threats to human exintence. The behavioral immune system had mechanisms to hunt or to kill pathogenic invaders. Unfortunately, these reactions left the people feeling sleepy and lethargic for which the sick ancestors did not enable to undertake hunting, gathering or childrearing.

The rise in body temperature during fever, cough, sneezing, or cold is essential for an effective immune response, but the results in $13 \%$ of increase in human body's energy consumption. When food is scarce, it may be a serious burden. Mark Schaller $\left.{ }^{3}\right]$ points out: "Getting sick, and allowing this wonderful immune system to actually work, is really costly [...] it is a kind of like medical insurance; it is great to have, but it really sucks when you have to use it."

When any medicine reduces the risk of infection at the primary stage, it offers a distinct survival advantage. Therefore, a man wants to evolve a subconscious psychological responses that the psychiatrist Schaller terms the "behavioral immune system" - to act as a defence in order that human contact with potential pathogens may be controlled.

The disgust response is a component of the behavioral immune system. When a man tries to avoid bad smell things, like dirty food, he tries to steer clear of potential contagion. When man eats rotten or dirty food, he wants to vomit; his digestion energy will get lessened; and he will suffer from dysentery. Psychological report shows that man intends to remember things that trigger disgust through remembering or avoiding the situations that lead a man into the risk of infection. Man is a social being for which he is bound to live together in a community or society. In this status man has been living in a group with the passage of time. Later, behavioral immune system modified his social interactions with other

${ }^{3}$. Professor of Psychology at the University of British Columbia. His expertise includes human psychology, social cognition, stereotyping, evolutionary psychology, and cultural psychology. people in the community so that they could control the outbreak of disease through maintaining social distancing. Such type of process seemed to be crude since people had no proper idea of the infected diseases by which process they were transmitted.

The impact of behavioral immune system varies from man to man. Lene Aarøe $\left[{ }^{4}\right]$ argues that there are some people who have sensitive behavioral immune system that makes them react extra-strongly to things that they interpret them as the potential infection risk. According to the psychological research, there are some people who are more respectful of social norms and more distrustful of outsiders than an average person. Such a threat of infectious disease hardens their mental condition.

In fact, man did not have any hard data on the ways that human mind is changing owning to the pandemic outbreak of the new coronavirus. Yoel Inbar $\left[^{5}\right]$ argues that the theory of behavioral immune system is a relatively moderate shift in overall opinion across the global population, rather than a huge lurch in social attitudes. Inbar finds evidence of social change during the 2014-Ebola epidemic when people realize about disease threats [8].

The theory of behavioral immune system makes us understand regarding the pandemic outbreak of coronavirus how a vast majority of population is now facing a terrifyingly difficult time around the world. The fear of coronavirus has created a social distancing between family members, relatives, friends, colleagues, and familiar ones around the world. As a social being man has been living together since ancient period to cope with natural environment. Psychological segregation between men is a difficult concern, which impacts negatively on human minds. Due to the outbreak of coronavirus, men are found to maintain distancing, for example, when a child or parent falls victim of coronavirus's infection, he is isolated in a solitary place; nobody is allowed to come in contact with such infected person. Again an infected person dies helplessly, no near and dearest one can touch him, or even no one dares to bury the dead body. Coronavirus medical team handles such tasks.

Social distancing, isolation, quarantine, home quarantine have created a great dilemma, trauma, and psychosocial conflicts in the minds of global population. Human psychology changes with the passage of events, especially when unknown or unseen pandemic outbreak is noticed. Coronavirus has created such a terrific sense which will indeed last long. To forget this situation, it

4. Associate Professor, Department of Political Science, Aarhus University.

5. Associate Professor of Psychology at the University of Toronto. Inbar studies on social, political, and moral beliefs. 
will take long period of time. It is a matter of great regret that no vaccine or medicine has been discovered yet. Nobody knows when this pandemic outbreak will be controlled.

\section{Impacts on Hoarding Supplies}

According to Stephanie Preston $\left[{ }^{6}\right]$, the word 'hoarding' may bring to mind relatives or neighbors whose houses are overfilled with junk. Some people may face hurdles or complexities what the psychologists have termed 'hoarding disorder.' They may reserve the excessive amount of goods in fear of distress and impairment. But, hoarding seems to be normal and adaptive human behavior; any time there can be an uneven supply of resources. There are many people who hoard necessary goods and food in a proper time without having conscious of hoarding supplies. They may have beans in the pantry, money in savings and chocolates hidden from children. These are all hoarding disorder. In fear of pandemic outbreak of coronavirus, many people of the world are found to reserve food or everyday necessary things at home. They think that if this difficult time is lengthy, they may have to fall into food crisis.

If an example is drawn to realize about hoarding disorder, the whole matter will seem to be clear to us. A wild beast, like squirrel is seen to hoard food so that it can eat throughout the year. Again a kangaroo rat in the desert collects seeds while it rains. They put seeds to dig them back up for the rest of the year. Ants seek food on the grass, on the way, on the muddy way. They dig hole to restore food so that they can eat throughout the year. Psychologists want to make us understand about the wild beasts, like squirrels and kangaroo rats which hoard their food to eat the rest of the year. Again tiny ants are found to hoard food, like paddy, wheat, and rice to eat the rest of the time.

According to the psychologists, similarities between human behavior and wild beast, like ants, squirrel, and kangaroo are not just analogies. They reflect an ingrained capability for brains to motivate human beings so that they may acquire and save resources for the rest of the year. Suffering from hoarding disorder, stockpiling in a pandemic or hiding nuts in the fall; these behaviors of man and animal are interconnected each other. But man is different from other creatures on earth, because man is a rational and intelligent being. Other creatures have no rational power like human being.

According to Preston, stress seems to signal the brain to switch into get hoarding mode. For example, a kangaroo will become lazy if it is fed regularly. But if its weight dropss down, its brain signals to release stress hormones that incite the

\footnotetext{
${ }^{6}$. Professor of Psychology, University of Michigan.
}

fastidious hiding of seeds all over the cage. A kangaroo will increase hoarding supplies if a neighboring animal steals seeds. After observation, Preston returns to the laboratory to find the victim of theft with the remaining food stuffed into his cheek pouches. He has tried to prove the fact that man will do the same thinks like a kangaroo [9]. Psychological point of view, hoarding disorder is generally seen during the pandemic outbreak period. Psychologists want to show the fact that hoarding disorder is closely dealt with coronavirus outbreak around the world where human brain works as a catalyst.

\section{Social Isolation}

Social isolation is a severe psychological and physiological stressor, and the stress of isolation is likely to hit those people who are devoted to significant energy and resources so that they can cope with daily life. These include the socially anxious, the unemployed, those with pre-existing mental health crisis, those at risk for domestic violence and child abuse, maltreatment, discriminatory attitudes, elderly people coping with hearing or eyesight problems, and those experiencing cognitive decline. Social isolation creates negative impacts on human brain and mind.

The novelty of coronavirus threat or crisis, uncertainty about its behavior, and the necessary adoption of restrictive measures to prevent its pandemic outbreak, like social isolation, create unusual conditions by giving rise to an unprecedented level of anxiety. According to psychologists and physiologists, when any man is socially isolated from other members due to the pandemic outbreak of coronavirus, he loses his normal pleasure and his sound health begins to decline.

\section{Anxiety and Fear}

Fear and anxiety occur at the same time; but, these psychological terms are not interchangeable. Even though anxiety and fear overlap typically, human experience with such symptoms varies from their context. Fear is related to a familiar threat, whereas anxiety follows from an unfamiliar threat.

Anyway, anxiety is an unpleasant sensation that normally serves as a stimulus to take an appropriate action in order that coronavirus can be curbed through necessary measurements. People refrain from the forms of activity. As a result, they feel helplessness due to the impact of anxiety. As governments, corporations, and individuals work to contain the spread of the virus, it is natural to experience stress or fear related to health, family, job, and economy. Though no man knows exactly what the next weeks or months will hold, many strategies have addressed the anxieties that emerge during the difficult time. These include physical steps, like prioritizing sleep and staying active, and emotional support, like challenging unhealthy thoughts and calling family and friends. Thus anxiety and fear owning to 
coronavirus crisis impacts negatively on human psychology [28].

\section{Healing}

Healing is a system of restoration of health from an unbalanced or infected organism. Its result can cure the cause of a health risk, while a man grows without cure $\left[{ }^{7}\right]$. According to the psychiatrists and psychologists, healing is a process for which neuroses and psychoses can be resolved so that people may maintain their normal lives. Within any challenge, there are opportunities. There is no question COVID-19 pandemic raises anxiety levels the world over, but for the substantial subsets of those with chronic mental health conditions, coronavirus crisis provides opportunities for a radical shift of the mindset or perspective that eases the burden of disorder. For many, having to meet day-to-day survival demands of epidemic through ensuring healthy food supply, maintaining sanitary routine, staying up-to-date on health-related information-relieves painful self-focus or provided distraction from the insecurities and obsessive thoughts with a view to giving the mind a healing rest.

\section{Remote Activity}

To maximize social distancing, more and more companies ask employees to work from home. In many locations, it is required by the law that nonessential workers may stay home, meaning that those who are able to work remotely must do so. Even in the best of times, transitioning to working from home may be a major adjustment. In the midst of a pandemic, anxiety and novel distractions, like children attending school from home, have made the shift more challenging than ever. Adopting strategies to minimize distractions and accepting that perfect productivity may be out of reach during this stressful time, may help man adapt to his new way of life.

Moreover, many teachers of educational institutions are taking their classes staying at home; assignments, class lecture, taking exam, and script assessments are currently provided through virtual system. Again many international seminars, conferences, and symposium are being held through webinar around the world. Many national and international companies, offices and industries are maintaining their functions through virtual system or online. Such types of activities can be called remote activity.

\section{Cognitive Bias $\left[{ }^{8}\right]$}

According to Haselton et al. cognitive bias deviates from rationality in human judgment. People create their own reality from perception of the input. Their construction of reality can dictate their behavior. Cognitive bias leads to perceptual distortion, inaccurate judgment, illogical interpretation, or irrationality [10].

Extraordinary events can provoke some unusual or even baffling responses from human beings. In the wake of this outbreak, we see everything from frantic mass purchases of toilet paper or hand sanitizer to blatant flouting of public health warnings and rules about social gatherings. The biases and heuristics long studied by psychologists may help us understand such phenomena. The tendency to play down the risk of unusual events, or normalcy bias, may be responsible for continued social congregation in spite of expert advice. For some, however, catastrophic thinking leads to going beyond the recommended precautions or overreacting to the signs of potential danger (Psychology Today)[28].

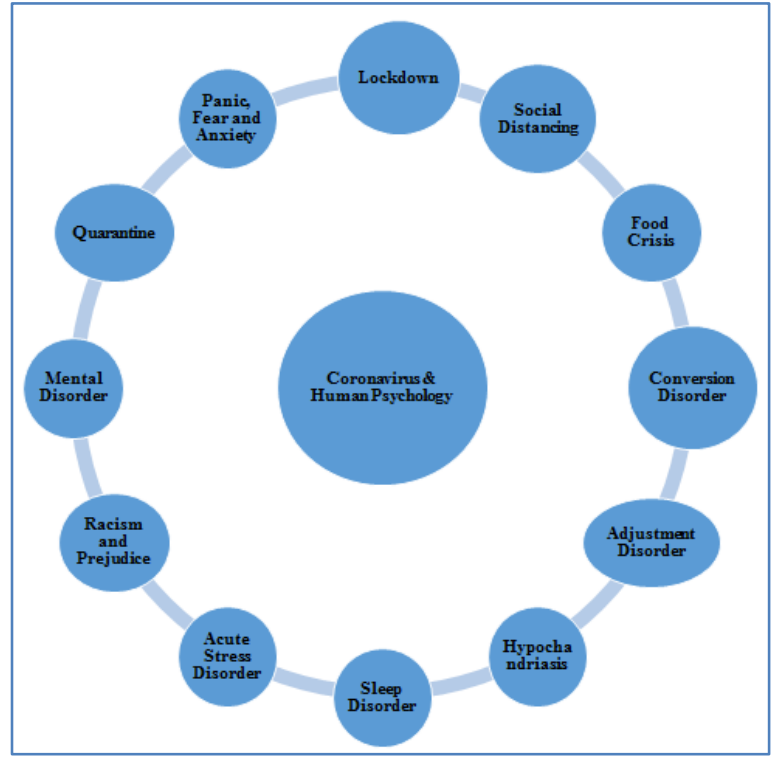

From this round-shaped wheel, the researcher wants to explain how human psychology changes during the pandemic outbreak of the novel coronavirus people living in the vulnerable countries of the world. Here he wants to expose the impacts of fatal coronavirus on human psychology. For this reason he has identified some conflicts, including lockdown, social distancing, hoarding supplies, superstition, mental disorder, quarantine, panic and fear so that he can highlight how the coronavirus is impacting human psychology each and every time. To conduct the

8. Cognitive bias is an error in human thinking capability that makes people process and interpret information. It is a result of human brain's attempt to simplify information processing. 
research-work, the researcher has mentioned some psychiatrists who have expressed their views regarding mental disorder during the pandemic outbreak of the novel coronavirus-19.

In this study the researcher would like to explain some reasonable human psychological problems, like food crisis, conversion disorder, sleep disorder, adjustment disorder, hypochondriasis, acute stress disorder, racism and prejudice, etc. through which we have to suffer from mental conflicts owning to the pandemic outbreak of the new coronavirus-19.

According to Sumant Kumar Saha [11], when a man is forced to maintain home quarantine due to the pandemic outbreak of coronavirus, he is not allowed to meet anybody in such a situation. He will not talk living a kind of isolated life. Even if a man gets rid of coronavirus, home quarantine can cause mental problems. There are some psychological problems, which may occur during this difficult time.

Bangladeshi psychiatrist Saha speaks about specific solutions of psychological concerns. During this time, older mental patients, (such as depression, bipolar disorder, anxiety disorder, panic disorder, obsessive compulsive disorder), who were healthy through medication, may return to the old problems in the wake of this panic. Again, many people are having various mental problems, who had not any mental illness before.

\section{Panic and Anxiety}

According to the psychological point of view, panic attacks generally happen to human being, but having more than one can be a symptom of panic disorder. On the other hand, anxiety attacks are not understood in the DSM-5 (Diagnostic and Statistical Manual of Mental Disorders)[26]. The DSM-5 regards anxiety as a feature of common psychiatric disorders. Symptomatic anxiety may include worry, distress, and fear.

Panic attacks are sudden onset of palpitations through trembling of hands and feet, sweating of the whole body, shortness of breath, chest pain or pressure, restlessness of the body, extreme heat throughout the body. Above all, it seems that the soul will go away from the body. This type of collective pain can last up to 10 minutes. Then, panic attacks slowly reduce to 30 to 40 minutes. This type of attack can occur several times a day.

\section{Acute Stress Disorder}

Isaac [12] points out that acute stress disorder is a psychological response to a terrifying and traumatic experience of a man. It is not fatal, but may happen delayed stress reactions if this stress is addressed in time. According to the Diagnostic and Statistical Manual of Mental Disorders (DSM-V), symptom presentation may last for three consecutive days to be identified as Acute Stress Disorder. If symptoms last one month, the diagnosis of Posttraumatic Stress Disorder (PTSD) needs to be investigated [13].

Acute stress disorder can lead to a variety of behavioral disorders, such as becoming less responsive to environmental problems during the pandemic outbreak of coronavirus, becoming incompatible with environment, forgetting everything. In a word, to suddenly become completely detached from this epidemic.

\section{Conversion Disorder}

According to the International Statistical Classification of Diseases and Related Health Problems, conversion disorder is a diagnostic category used in the psychiatric classification systems. It is applied to those patients who are diagnosed by neurological symptoms, like numbness, blindness, or paralysis inconsistently with an organic cause, which occur mental distress, and may be traced back to the psychological trigger. Symptoms of conversion disorder arise in a response to the stressful condition through affecting the patient's mental health condition, like depression and anxiety [14].

In the case of conversion disorder, the patient often becomes unconscious. He lies unconsciously with his eyes closed. This condition can last from a few minutes to a few hours. At this time, the patient is called, but no response will be received. However, in this state of unconsciousness, the patient hears everything but cannot speak, even cannot open his eyes.

\section{Adjustment Disorder}

An adjustment disorder brings about while a man has significant difficulty adjusting to or dealing with a significant psychosocial stressor. This disorder is common among many of us. Sadness, hopelessness, lack of enjoyment, crying spells, nervousness, anxiety, desperation, overwhelming, or suicidal acts are the main symptoms of adjustment disorder. This disorder causes instability in the patient's mind. His mind becomes exhausted. He is severely tensed and broken heart. Again, he will have to face behavioral problems, like crying, talking incoherently.

\section{Hypochondriasis}

According to Berrios [15], hypochondriasis is a condition in which a person is excessively and unduly concerned of his severe illness (p.3). Some people may have intrusive thoughts and physical sensations that push them to check with family, friends, and physicians. For example, a when a patient coughs, sneezes, or spits, he may think that he may be infected by the novel coronavirus. 
In the case of hypochondriasis, if the patient shows the slightest signs of coronavirus infection, like sore throat, seasonal fever, cold, he becomes very anxious and thinks that he is infected with coronavirus. The same thoughts are kept swirling in his head all the time and he becomes anxious to do various tests, including coronavirus detection test.

\section{Sleep Disorder}

Hirshkowitz [16] points out that sleep disorder is a medical disorder of the sleep patterns of a patient. Some sleep disorders are serious enough to interfere with the normal physical, mental, social and emotional functioning. Disruptions in sleep may be caused by a variety of issues, such as teeth grinding and night terrors. When a patient suffers from difficulty falling asleep or staying asleep with no obvious cause, it is referred to as insomnia. (p.315) Sleep disorders can cause a variety of sleep problems during the pandemic outbreak of coronavirus, for example, being late to sleep, having various worries after going to bed, waking up repeatedly, having nightmares in sleep, and talking in sleep, etc.

The researcher personally feels sleep disorder or have to pass sleepless nights. It seems that panic is too much us. When the pandemic outbreak will be gone away and when better days will come again, we are awaiting the moment. Certainly, sleep disorder is a psychological problem for many of us at this terrifyingly difficult situation.

\section{Remedies}

Most of the above-mentioned psychological conflicts caused by the pandemic of the novel coronavirus are immediate, meaning that once the coronavirus infection is gone, most human psychological problems will gradually go away. In order to relieve people of various mental problems at the moment, very fast anxiety reducing drugs, like angiolytics are being prescribed for a short period of time: 3 to 6 weeks. As a result, people may temporarily get relief. Very few people, whose problems will not be removed, may need long-term treatment.

Seeing the patient is the best treatment. However, in this difficult situation, if the patient and his family come to the doctor for treatment, the possibility of the coronavirus infection may increases and the lockdown will not be successful. For this reason the patient needs tele-consultation, like telephone, video calling via Whatsapp, Google Hangouts, and Skype at this time.

Older patients who keep sound health by taking medicine can continue the medication by talking to the doctor on the phone. If an old patient has a new problem or a healthy person who has no previous mental illness has a mental problem, the doctor should be notified by telephone or video calling. In most cases, the patient can solve his mental problems via telephonic conversation. If the problem is not solved, he should go to a doctor in a protected place, like government hospital or private clinic [11].

\section{Social Distancing}

The longest lockdown in the history of the world is going on in the pandemic outbreak of coronavirus. One fifth of the global population is under home quarantined or house-arrest. Mental stress and uncertainty can cause unprecedented damage to mental health around the world. Experts say that social distancing may lead to widespread anxiety and depression. Although there has not been much research on this subject still now.

A review of research on psychological effects in a Scientific Journal Lancet opines that lockdown may have a long-term negative impacts on the minds of many people. Researchers study 2,760 people. They find that $34 \%$ of people suffer from mental health problems due to quarantine. They are suffering from mental health problems, like anxiety and depression.

According to a psychiatrist and mental health expert at Uniformed Services University in the United States, adhering to social distancing will make some people feel unwell. Frustration, anxiety will be created in human mind. Adhering to social distancing is a very difficult time for someone.

Anxiety and depression due to coronavirus is added to real problems, financial problems, earning problems and separation from loved ones, which also challenge the mental health of the people. For a large population, this will be a great problem. People are all talking about social distancing. In fact, what people need is physical distancing, not social distancing, because it gives the wrong message. On the contrary, in this difficult time, people need more social cohesion, more social support than social isolation.

If it is possible without compromising the fight against the coronavirus, a man should be encouraged. The real message should be to maintain physical distancing, to take the necessary security; but, at the same time to have a sense of social unity, which can be observed while maintaining physical distancing. Talking to people on the phone, talking to each other, helping each other with problems may be great weapons to fight against the coronavirus [17].

It is difficult for everyone to wash their hands frequently and maintain social distancing to avoid coronary heart disease. However, 450 million people in the world are now in a big challenge for coronavirus infection. At this moment about 450 million people are suffering from mental disorder. The Senior Physician, Department of Psychiatry and Psychotherapy, Dresden University Hospital, and the Chairman of German 
Society for Suicide Prevention, Uta Levitsoka comments: People with psychiatric illness carry an extra burden on their backs. Sometimes there comes a time when the burden seems relatively light. Then, it is possible to adapt well to daily life. But sometimes there are times when that burden seems to be heavier. Their lives will become miserable when conditions, like external pressure or being under pressure will be prolonged.

Psychiatry, depression and danger for which some people are more afraid of the coronavirus. It is not uncommon to be more afraid of a danger that cannot be seen with the naked eye, where it is and where it is not. However, if a man is physically healthy, he feels strong. Experts say that mentally ill people with having weak body will have a great risk of getting infected. Earlier, a man can consult a doctor. Now both the patient and the doctor will have to follow the rules of social distancing. In this situation, many people are seen to discuss with the doctor on the phone or video call as an alternative way[25].

\section{Racism and Prejudice}

The pandemic outbreak, which starts in the city of Wuhan, Hubei, China, in December 2019, leads to an increase in acts and displays of prejudice, discrimination, violence, and racial conflicts against the Asian descent and appearance around the world. As the situation spreads in Europe, Middle East, Australia, Russia, and the United States, at the same time the discriminatory acts against the Chinese are greatly noticed through social media, like Face Book, Yahoo News, BBC, CNN, Twitter, and above national newspapers globally.

According to Ghani [18], racism is a concept that a group of human possess different behavioral traits through corresponding to physical appearance and can be divided based on the superiority of one race over another. It may include prejudice, discrimination, or antagonism being directed against other people because they are of a different race or ethnicity (p.1113). In social and behavioral sciences, sociologists regard race as a social construct. Though the concept of race and racism is based on the biological features, racism exists in a society at both individual and institutional level.

Cazenave and Maddern [19] define racism as a highly organized system of race-based group privilege that operates at every level of society. It is occurred by the sophisticated ideology of color or race supremacy. Racial centrality affects discrimination that African American young adults have to tolerate whereas racial ideology may buffer the detrimental emotional effects of that discrimination. (p.25) Sellers and Shelton [20] point out that a relationship between racial discrimination and emotional distress is moderated by racial ideology and social beliefs. (p.1079)
Prejudice refers to unfounded beliefs. It is an unreasonable attitude that is resistant to rational influence. Dovidio and Gaertner [21] think that prejudice is an affective feeling towards a person based on their perceived group membership. The term refers to a preconceived and unfavorable evaluation of another person based on that person's political affiliation, like sex, gender, beliefs, social class, age, religion, sexuality, race, language, nationality, or other individual characteristics.

Gordon Allport [22] deems prejudice as a "feeling, favorable or unfavorable, toward a person or thing, prior to, or not based on, actual experience." (p.6). Moreover, Auestad [23] regards prejudice as characterized by symbolic transfer, transfer of a valueladen meaning content onto a socially formed category; and then, on to human beings who are taken to belong to a category, resistance to change, and overgeneralization. (p. xxi)

From the theory of racism and prejudice, we understand that coronavirus has created a racial prejudice among the minds of the global community, especially in the United States of America. Many Chinese living in America for different purposes have to face mental conflicts at every step of life. As we all know that coronavirus is originated in the Wuhan city in China. Slowly, the infected virus breaks out all over the countries of the world. Due to its pandemic outbreak a vast majority of population is dying and getting infected and affected at every moment. As a matter of fact, racial prejudice against the Asian nations is created in the minds of the global communities. It is seen that coronavirus infection has created communal segregation, racial conflicts and prejudice among the global population.

According to three international organizations, failing to prevent the spread of the coronavirus may lead to a global food crisis. These agencies, like Food and Agriculture Organization of the United Nations, World Health Organization and World Trade Organization, point out that the governments of every country around the world have taken various measures, including lockdown and quarantine, in an effort to prevent the pandemic spread of coronavirus. In this situation, the international trade and food supply system has collapsed. Many panic stricken people have already stockpiled food through creating a crisis in the supermarkets in many countries of the world. The supply system is on the verge of collapsing.

It is added that while the vulnerable countries of the world are working to ensure the health and wellbeing of their citizens, trade-related measures will not disrupt the food supply system; that matter must be taken into an account. Prolonged blockade and restrictions on the public movement will threaten agricultural production due to the lack of access to 
agricultural labor and non-availability of food products in the international markets. In addition, these top officials emphasize on the need to protect, process and distribute food to the workers involved in food production. At the same time, the global agencies opine that international cooperation is essential to avoid food crisis immediately.

The statement says that uncertainty over easy availability of food products may increase export restrictions; and, at the same time, it may create food shortages in the global markets. Every effort made in the lockdown to prevent coronavirus must be taken in such a way so as to ensure free trade flow as much as possible, especially to avoid shortages of food or food crisis.

In the Financial Express, Ranjan Roy $\left[{ }^{9}\right]$ points out that coronavirus is creating food crisis in the vulnerable countries of the world. In some areas, lockdown strategy has been followed to prevent the coronavirus infection. This strategy has imposed a plethora of COVID-19 by protecting measures, such as market, supply chain and trade disruptions that have significantly affected agricultural production, food supply, and demand.

About 820 million people have to face hunger and mental disorder. They have no ability to eat proper food for keeping a sound health. They are vulnerable to disruptions to access to food. Similarly, low-income farmers are vulnerable who are hindered from working on land or accessing markets to sell their products and buy seeds and other necessary commodities.

Protectionist measures across the globe may aggravate the COVID-19 impact. If any country banns exports of wheat flour, rice, or paddy, especially developing countries have to face food crisis during the pandemic situation. Vietnam, for example, the world's third-biggest rice exporter, has temporarily suspended rice export contracts. Advocates opine that trade barriers will create extreme volatility. Panic-buying disrupts food distribution. As the pandemic situation breaks out, many people are stockpiling staples temporarily through leaving markets empty.

Agricultural economists are concerned of the current and imminent implications of the terrifyingly difficult situation. Food supply chain is a complex web that involves producers, agricultural inputs, transportation, processing plants, shipping etc. Disruptions are now minimal as food supply is adequate, and markets are stable. Experts thinks that current closures to transport route, transport restrictions

9. Associate Professor, Department of Agricultural Extension and Information System, Sher-e-Bangla Agricultural University, Bangladesh. and quarantine measures, shortages of labor, and spikes in product's prices are obstructive for food supply chains and result in increased levels of food loss and waste. These obstructions are likely to impede farmers' access to markets through curbing productive capacities and hindering them from selling their products in the national markets. Shortages of labor may disrupt the production and processing of food.

Coronavirus infection is affecting food supplies in various ways. Poor income source and uncertainty will make people spend less and result in shrinking demand. During the lockdown, people are forbidden to go to the markets that affect their food choice; and they are buying cereal crops and consumption, a rise in eating food at home. Food demand is connected to income source. Poor people's loss of income source opportunities may impact on consumption. The UN's food body warns that protectionist measures by the governments during the coronavirus crisis can provoke food shortages around the world [24].

In fear of food crisis the globally vulnerable communities are still now found to hoard food. They think that if this pandemic situation becomes lengthy and long term, they cannot afford to meet the basic human needs, especially food. Food crisis is one of the major challenges for the coronavirus-affected people, including Bangladesh. Psychologists opine that food crisis creates a mental trauma in the people's minds. For this reason, at the very outset of the pandemic outbreak, the possible vulnerable communities are found to hoard food just like the animals. Ants, for example, make holes to procure food so that they can eat the rest of the year.

In Bangladesh content, the researcher thinks that 'Savlon' (a powerful germicide liquid) crisis is found in the capital city just before the pandemic outbreak. People are found to seek this germicide liquid in many shops or medicine stores, but, no a single liquid is available. The reason is that people feel panic and anxiety in this sense that food crisis may occur during the pandemic outbreak of the coronavirus. Panic stricken people do such unwise acts. But they must realize the fact that those who are poverty-stricken or downtrodden communities what they will do in this terrifyingly difficult time. They have also families. They should be given opportunities to buy food or other essential commodities. Panic and anxiety lead the communities to hoard food during the pandemic outbreak. Coronavirus crisis is a glaring example of human psychology.

\section{CONCLUSION}

The current researcher has tried to highlight the impacts of the novel coronavirus on human psychology through the pandemic outbreak in the vulnerable countries of the world. For this purpose, the 
study has discussed on human body and brain, prejudice, hoarding supplies, social isolation, quarantine, home quarantine, anxiety, fear and panic, healing, remote activity, cognitive bias, acute stress disorder, conversion disorder, adjustment disorder, hypochondriasis, sleep disorder, social distancing, and racial conflicts of the global communities in the light of the critical comments made by the psychological and sociological critics and scholars, like Lunstad, Miller, Faulkner, Light, Ermon, Preston, Haselton, Saha, Levitsoka, Allport, Auestad, Roy and so on. Through their opinions and judgments, the study has wanted to investigate the psychological trauma and mental disorders based on the infection and affection of the coronavirus. Moreover, the statements and opinions regarding the pandemic outbreak of the coronavirus and its severe impacts on the global population made by the World Health organization, the World Trade Organization, the Food and Agriculture Organization, and above all, American Psychiatric Association have been prioritized in this discussion with a view to upholding the prevalent terrifyingly difficult situation. How the human behavioral immune system has created the racial prejudice in the coronavirus infected countries, especially USA, and Europe is the dominant aspect of this study.

Social distancing, isolation, quarantine, and home quarantine have created a great dilemma, trauma, and psychosocial conflicts in the minds of the global communities. Human psychology is changing owning to the deadly attacks of the virus. The coronavirus threat, crisis, or uncertainty about its behavior, and the necessary adoption of restrictive measures to prevent its pandemic outbreak has created the unusual conditions by giving rise to the unprecedented level of anxiety, fear, and panic. Social distancing, home quarantine, and isolation have negatively impacted on many younger and older generations in many countries of the world. The normal living condition of the communities has been paralyzed economically, socially, culturally, politically and above all, psychologically. Millions of people around the world have fallen victim of poverty, hunger, malnutrition, unemployment, and financial crisis. The whole world has become stagnant. All these aspects as mentioned above have severely impacted on human psychology. For this purpose, this study has emphasized upon noticeable human psychological conflicts. But, it is a matter of great regret that no vaccine or medicine has been discovered yet. Nobody knows when this pandemic outbreak will be controlled; how mankind will get rid of this situation; and when better days will come again is the sole expectation.

\section{REFERENCES}

1. Miller, Anna Medaris. "What coronavirus quarantine does to your body and brain, and how to cope." Business Insider; 2020.

2. Duncan LA, Schaller M. Prejudicial attitudes toward older adults may be exaggerated when people feel vulnerable to infectious disease: Evidence and implications. Analyses of Social Issues and Public Policy. 2009 Dec; 9(1):97-115.

3. aulkner J, Schaller M, Park JH, Duncan LA. Evolved disease-avoidance mechanisms and contemporary xenophobic attitudes. Group Processes \& Intergroup Relations. 2004 Oct; 7(4):333-53.

4. Mortensen CR, Becker DV, Ackerman JM, Neuberg SL, Kenrick DT. Infection breeds reticence: The effects of disease salience on selfperceptions of personality and behavioral avoidance tendencies. Psychological Science. 2010 Mar; 21(3):440-7.

5. Schaller M, Park JH. The behavioral immune system (and why it matters). Current directions in psychological science. 2011 Apr; 20(2):99-103.

6. Huang JY, Sedlovskaya A, Ackerman JM, Bargh JA. Immunizing against prejudice: Effects of disease protection on attitudes toward out-groups. Psychological Science. 2011 Dec; 22(12):1550-6.

7. Nicomedes CJ, Avila R. An Analysis on the Panic of Filipinos During COVID-19 Pandemic in the Philippines.

8. Robinson David. "The fear of coronavirus is changing our psychology." BBCFuture;2020.

9. Preston, Stephanie. "COVID-19: Why hoarding supplies is human nature, according to a psychologist." World Economic Forum; 2020.

10. Haselton MG, Nettle D, Murray DR. The evolution of cognitive bias. The handbook of evolutionary psychology. 2015 Nov 23:1-20.

11. Saha, Sumant Kumar. "What sorts of mental problems may be occurred during home quarantine.” Dhaka Times; 2020.

12. Isaac Jeff. Wilderness and rescue medicine. Jones \& Bartlett Learning; 2013.

13. DSM-5 American Psychiatric Association. Diagnostic and statistical manual of mental disorders. Arlington: American Psychiatric Publishing. 2013.

14. Tollison CD, Satterthwaite JR, Tollison JW, editors. Practical pain management. Lippincott Williams \& Wilkins; 2002.

15. Berrios GE. Hypochondriasis: History of the concept. Hypochondriasis: Modern perspectives on an ancient malady. 2001:3-20.

16. Hirshkowitz M. Chapter 10, Neuropsychiatric Aspects of Sleep and Sleep Disorders (pp 315-340). Google Books preview includes entire chapter 10). Essentials of neuropsychiatry and clinical neurosciences. 2004;4.

17. The Kalerkantho. "Mental problems can increase social distancing;"2020.

18. Schaefer RT. Encyclopedia of race, ethnicity, and society. Sage; 2008 Mar 20.

19. Cazenave NA, Maddern DA. Defending the white race: white male faculty opposition to a "white racism" course. Race and Society. 1999 Jan $1 ; 2(1): 25-50$. 
20. Sellers RM, Shelton JN. The role of racial identity in perceived racial discrimination. Journal of personality and social psychology. 2003 May;84(5):1079.

21. Dovidio JF, Gaertner SL. Intergroup bias. Handbook of social psychology. 2010 Jun 30.

22. Allport G. The Nature of Prejudice: [sl] Perseus Books Publishing.

23. Auestad Lene. Respect, Plurality, and Prejudice. London: Karnac; 2015. xxi.

24. Boughton D, Goeb J, Lambrecht I, Mather D, Headey DD. Strengthening smallholder agriculture is essential to defend food and nutrition security and rural livelihoods in Myanmar against the
COVID-19 threat: Elements for a proactive response. Intl Food Policy Res Inst; 2020 Apr 16.

25. Carthouse, Anna. "Coronavirus, mental health and the hard reality of social distance." Adjusted Cost Base.

26. Diagnostic and Statistical Manual of Mental Disorders $\left(4^{\text {th }}\right.$ edition). American Psychiatric Association.

27. Light, Alysson E. "Psychology of Coronavirus." Society for Personality and Social Psychology; 2020.

28. Psychology Today. "Coronavirus Disease 2019: COVID-19." 